\title{
EFFECTS OF LIGHT WAVELENGTH ON DAUGHTER CLADODE GROWTH AND QUALITY IN EDIBLE CACTUS NOPALEA COCHENILLIFERA CULTURED IN A PLANT FACTORY WITH ARTIFICIAL LIGHT
}

\author{
Takanori HORIBE*, Shousei IMAI, Takuya MATSUOKA \\ College of Bioscience and Biotechnology, Chubu University \\ Kasugai 487-8501, Japan
}

Received: August 2018; Accepted: April 2019

\begin{abstract}
In this study, we investigated the effects of different-colored light-emitting diodes (LEDs) on the growth and quality of daughter cladodes of the edible cactus Nopalea cochenillifera. Cladodes were cultured hydroponically using the deep-flow technique under red, blue, or a combination of red and blue, or red, blue, and green light in an enclosed-type plant factory. We found that daughter cladodes developed from the mother cladodes in all the treatments, despite $\mathrm{pH}$ of the nutrient solution drastically decreasing over time. However, the elongation growth rate of the first daughter cladodes and the number of daughter cladodes produced were highest under red light and lowest under blue light, indicating that blue light suppresses daughter cladode development. The total fresh weight $(\mathrm{FW})$ of the daughter cladodes emerging from a single mother cladode was also lowest under blue light. However, the average FW of the daughter cladodes was the highest under blue light, or under simultaneous irradiation with red and blue light. The number of spines, which is an undesirable characteristic in edible cacti, was significantly lower under red light than under blue light, while the 2,2-diphenyl-1-picrylhydrazyl (DPPH) radical scavenging activity of the daughter cladodes was the highest under blue light or under simultaneous irradiation with red and blue light. Our results show that light wavelength has a strong effect on daughter cladode development in $N$. cochenillifera, so controlling the light environment represents an effective approach for improving the growth and quality of this edible cactus.
\end{abstract}

Keywords: Antioxidant status, LED, spines, plant factory, productivity, light spectrum

\section{INTRODUCTION}

Edible cacti have been used by humans for hundreds of years in a variety of ways, including as animal feed, fruits, and vegetables for human consumption, a source of nutraceutical compounds, and in the production of natural dyes such as cochineal red (Guzmán-Maldonado \& Paredes-López 1999; Silos-Espino et al. 2006). For example, stems of prickly pear cacti, which include over 100 species in the genera Nopalea and Opuntia that are native to Mexico, are widely consumed as a vegetable in Mexico, Latin America, South Africa, and Mediterranean countries (Cruz-Hernández \& ParedesLópez 2010; El-Mostafa et al. 2014; Stintzing \&
Carle 2005). In some countries, edible cacti are also used as folk remedies for a range of health problems, including burns, edema, and indigestion (ElMostafa et al. 2014; Shetty et al. 2012). In Japan, edible cacti are mainly produced in Kasugai City, Aichi Prefecture; however, the production scale here is still small.

Edible cacti are a major source of fruits, vegetables, and forage in areas with very low yields of traditional cultivars due to poor soil quality (GarcíaSaucedo et al. 2005), and prickly pear cacti also have a high capacity for adaptation to different environmental conditions, particularly arid and semiarid climates. However, major problems are commonly encountered when growing vegetables in 
soil; these include soil-borne diseases, salt accumulation, and difficulties in fertilizer management (Lakkireddy et al. 2012). Hydroponics is an alternative method of growing plants that uses nutrient solution (water and fertilizer) with or without an artificial medium and can be used for the production of several crops. This method has several advantages, such as avoiding the requirement for soil sterilization to prevent soil-borne diseases, which is both costly and time-consuming, and enabling precise fertigation management (Lakkireddy et al. 2012; Wahome et al. 2011). In addition, hydroponics can be used to reduce the nitrate (Stefanelli et al. 2011; Wang et al. 2007) and potassium (Ogawa et al. 2012) contents of vegetables, the reduction of which is beneficial to human health, as the former can be converted to harmful nitrites in humans and the latter is often restricted in the diet of dialysis patients. We have previously shown that edible cacti can be grown in a simple hydroponic culture system using commercially-available materials (Horibe 2017; Horibe \& Yamada 2016). However, this method is not yet practiced commercially.

Hydroponics is used as a basic cultivation system in plant factories, which are horticulture greenhouses or automated facilities where vegetables and other crops can be produced throughout the year by controlling the environmental conditions, such as light, temperature, humidity, $\mathrm{CO}_{2}$, and nutrient availability (Hirama 2015; Yanata \& Takata 2014). Light is essential for plants, with both the wavelength and intensity affecting plant growth and morphogenesis (Mortensen \& Strømme 1987; Yanagi et al. 2006), and previous studies have shown that light intensity affects the elongation growth of the stems and the malate content of the cladodes in cacti (Littlejohn \& Ku 1985; North et al. 1995). However, few studies have investigated the relationship between the light environment and cladode growth in edible cacti, an understanding of which is important for improving the production and quality of these crops. Therefore, in this study, we investigated the effects of different-colored light-emitting diodes (LEDs) on the growth and quality of the edible cactus Nopalea cochenillifera (L.) Salm-Dyck under hydroponic conditions.

\section{MATERIALS AND METHODS}

\section{Plant materials}

Nopalea cochenillifera cladodes averaging $16 \mathrm{~cm}$ in length, $7 \mathrm{~cm}$ in width, and $1 \mathrm{~cm}$ in thickness were harvested at a commercial cactus farm (Goto saboten) in Aichi Prefecture, Japan, in April and August 2017. Within 1 hour of collection, the cladodes were transported under dry conditions to the laboratory at the College of Bioscience and Biotechnology, the Chubu University, Kasugai, Japan, where they were trimmed to a length of $13.5 \mathrm{~cm}$.

\section{Light treatments}

The cladodes were cultivated using a two-layer hydroponic system (Churitsu Electric Co., Japan) with the deep-flow technique in an enclosed-type plant factory (Fig. 1A). OAT House solution A (Otsuka AgriTechno Co., Ltd., Japan; electrical conductivity $=2.6 \mathrm{mS} \cdot \mathrm{cm}^{-1}$ ) was used as the hydroponic nutrient solution, which was prepared by dissolving $150 \mathrm{~g}$ of Otsuka House 1 and $100 \mathrm{~g}$ of Otsuka House 2 in $100 \mathrm{dm}^{3}$ of water. The cladodes were transplanted into cultivation panels $(88 \mathrm{~cm}$ long $\times 57 \mathrm{~cm}$ wide $\times$ $4 \mathrm{~cm}$ high) with an inter-plant spacing of $4.5 \mathrm{~cm}$ and an inter-row spacing of $4 \mathrm{~cm}$, which were then floated on the nutrient solution in cultivation beds (90 cm long $\times 60 \mathrm{~cm}$ wide $\times 8 \mathrm{~cm}$ high).

The cladodes were separated into four treatment groups ( $\mathrm{n}=16$ cladodes per group), which were placed under different-colored LEDs (Churitsu Electric Co., Japan): (1) red light, peak emission $=660 \mathrm{~nm}$ (Red); (2) blue light, peak emission $=440 \mathrm{~nm}$ (Blue); (3) simultaneous irradiation with red and blue light with the ratio of $1: 1(\mathrm{R}+\mathrm{B})$; (4) simultaneous irradiation with red, blue, and green light with the ratio of $1: 1: 1$, peak emission of green light $=525 \mathrm{~nm}(\mathrm{R}+\mathrm{B}+\mathrm{G})$. The relative spectral photon flux distribution of the LEDs used in this experiment was measured using a light analyzer (Nippon Medical \& Chemical Instruments Co., Japan) (Fig. 2). The cladodes were grown under a 14hour light period (photosynthetic photon flux density $\left.=150 \mu \mathrm{mol} \cdot \mathrm{m}^{-2} \cdot \mathrm{s}^{-1}\right)$ and a 10 -hour dark period, and the cultivation room inside the enclosed-type plant factory was maintained at a temperature of $28^{\circ} \mathrm{C}$ and a relative humidity of $60-80 \%$. 

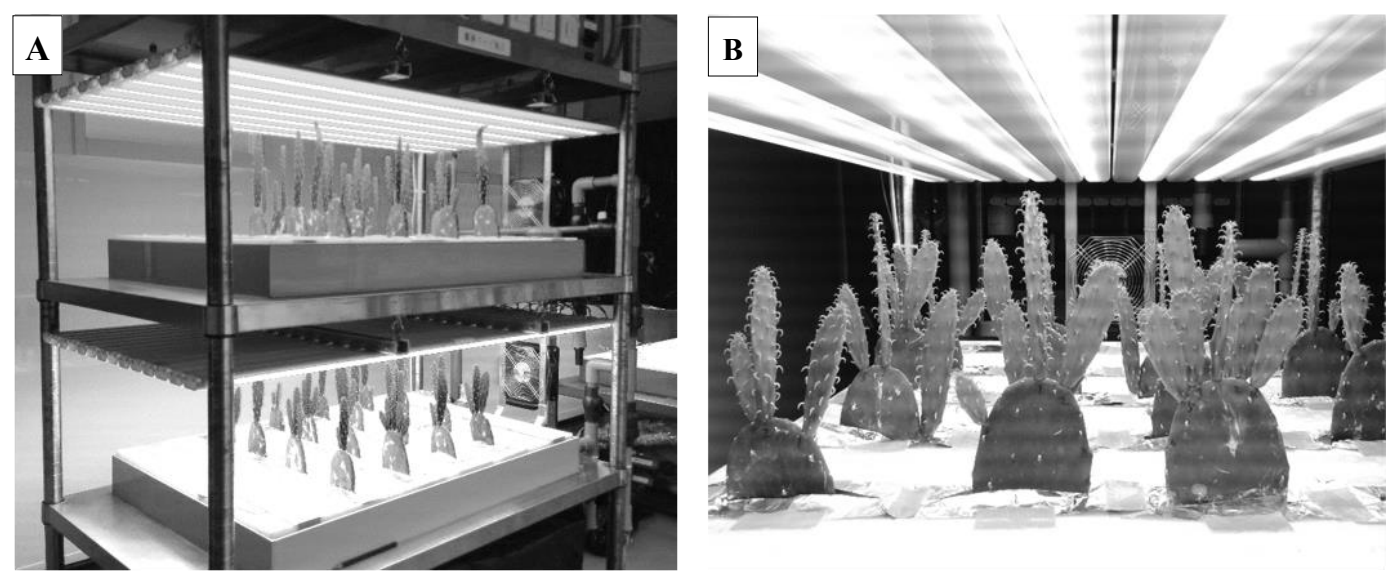

Fig. 1. Photographs of the hydroponic culture system used to grow the edible cactus Nopalea cochenillifera under artificial light (A) and the daughter cladodes that emerged from a mother cladode (B)

\section{(A) Red}
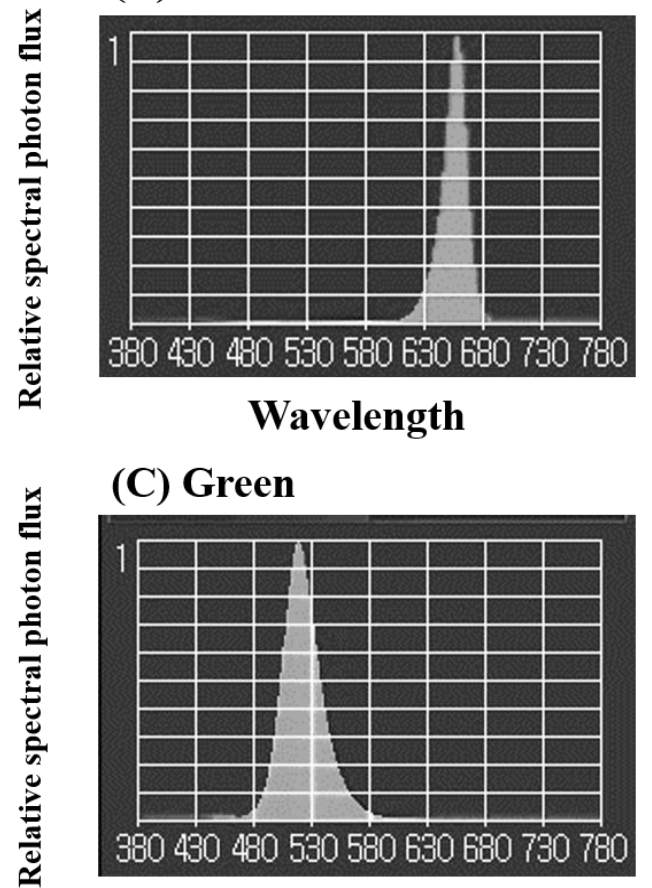

Wavelength
(B) Blue

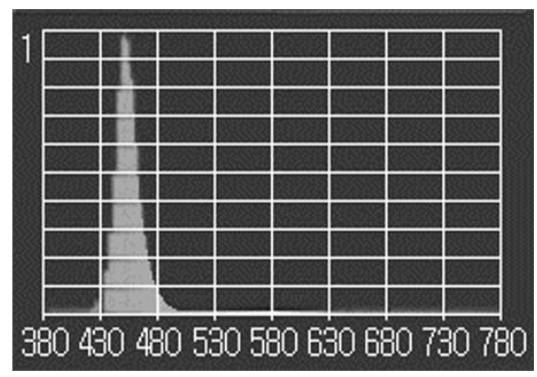

Wavelength

Fig. 2. Relative spectral photon flux distributions of the light-emitting diodes (LEDs) used in this experiment. (A) red light, (B) blue light, (C) green light

The numbers of daughter cladodes produced and the lengths of the first daughter cladodes were measured weekly. The daughter cladodes were then harvested and weighed when they reached a height of $18 \mathrm{~cm}$ (when they reached the LED panel). In addition, the number of areoles having spines was counted on 13 daughter cladodes from each treatment group and spine occurrence was then calculated as spine occurrence $=$ (total number of areoles with spines longer than $1 \mathrm{~mm}$ )/(total number of areoles). When a mother cladode had multiple daughter cladodes, the mean spine occurrence was calculated. 


\section{2,2-diphenyl-1-picrylhydrazyl (DPPH) radical scavenging activity}

The antioxidant scavenging activities of five daughter cladodes in each treatment group were determined using the DPPH method. A 1-g sample of each daughter cladode was homogenized in $5 \mathrm{ml}$ of methanol: water $(6: 4 \mathrm{v} / \mathrm{v})$, and the resulting homogenate was centrifuged at $6,000 \times \mathrm{g}$ for $10 \mathrm{~min}$ at room temperature. The capacity to scavenge the "stable" free radical DPPH was monitored following the method of du Toit et al. (2001). The DPPH assay was initiated by adding $23 \mu \mathrm{l}$ of the homogenate to a microplate well containing $210 \mu \mathrm{l}$ of $0.6 \mathrm{mM}$ DPPH methanolic solution (Tinyane et al. 2013). The reaction mixture was then left at $25^{\circ} \mathrm{C}$ for $60 \mathrm{~min}$, following which the decrease in absorbance at $515 \mathrm{~nm}$ was measured using a microplate reader. In addition, a solution of 6-hydroxy-2,5,7,8tetramethylchroman-2-carboxylic acid (Trolox) was prepared immediately before the analysis and used as a positive control and the same reagents were used without the addition of extract as a negative control. The antioxidant scavenging activities were expressed in $\mu \mathrm{g}$ of Trolox $\mathrm{g}$ fresh weight $(\mathrm{FW})^{-1}$.

\section{Statistical analysis}

All the experiments were performed twice (initiated in April and August 2017). Data were subjected to analysis of variance, and the significance of the differences across means were defined using Tukey's test at significance level of $p=0.05$.

\section{RESULTS}

\section{Length and number of daughter cladodes}

Surprisingly, the $\mathrm{pH}$ of the nutrient solution for all the treatments drastically decreased to approximately 2.5 during the course of the experiment, whereas its electrical conductivity (EC) exhibited no real change (Fig. 3A and 3B). In all the treatment groups, daughter cladodes developed from the mother cladodes during the first two weeks of the experiment (Fig. 2B) and continued to elongate until harvesting, with the rate of elongation of the first daughter cladodes being highest in the red treatment group, lowest in the blue treatment group, and intermediate in the $\mathrm{R}+\mathrm{B}$ and $\mathrm{R}+\mathrm{B}+\mathrm{G}$ treatment groups (Fig. 4A). In all treatment groups, the number of daughter cladodes rapidly increased during the first three weeks and then became fairly stable until six weeks after treatment, at which time there was another increase until the end of the experiment (Fig. 4), with the red and $R+B+G$ treatment groups producing the largest numbers of daughter cladodes, and the blue treatment group producing the fewest. The width of the daughter cladodes was significantly greater in the blue and $\mathrm{R}+\mathrm{B}$ treatment groups than that in the red and $\mathrm{R}+\mathrm{B}+\mathrm{G}$ treatment groups (Fig. 5).

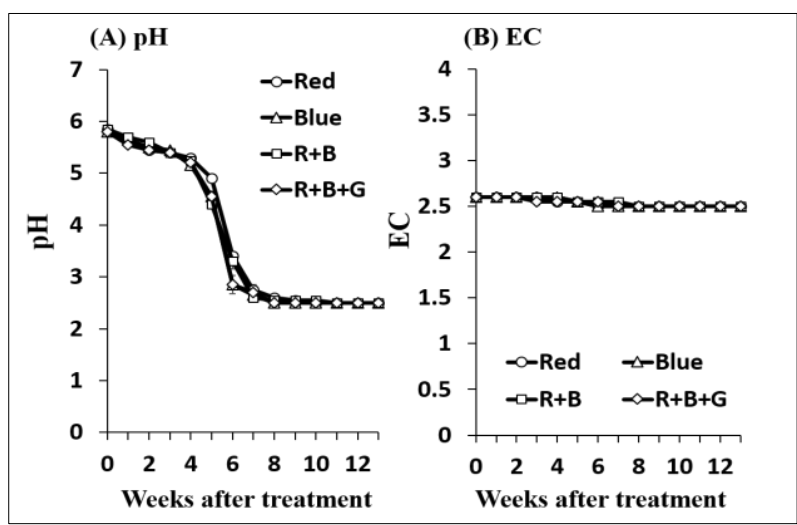

Fig. 3. Changes in the $\mathrm{pH}(\mathrm{A})$ and electrical conductivity (B) of the hydroponic nutrient solution during the course of the experiment. Values are means \pm standard error $(\mathrm{SE})(n=2)$

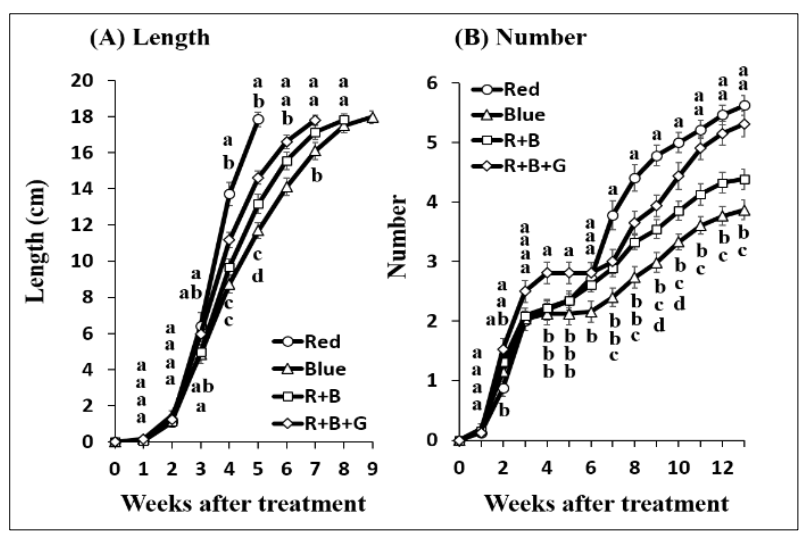

Fig. 4. Length of the first daughter cladode (A) and number of daughter cladodes produced (B) in each treatment group. Means followed by a different letter within each week are significantly different, according to the least significant difference $(\mathrm{p}<0.05)$. Values are means $\pm \mathrm{SE}$ $(n=32)$. Red, red light treatment; Blue, blue light treatment; $\mathrm{R}+\mathrm{B}$, combined irradiance with red and blue light $\mathrm{R}+\mathrm{B}+\mathrm{G}$, combined irradiance with red, blue, and green light 


\section{Average and total fresh weight of the daughter cladodes}

The average FW of the daughter cladodes was highest in the blue and $\mathrm{R}+\mathrm{B}$ treatment groups and lowest in the red treatment group (Fig. 6A), while the total FW of the daughter cladodes harvested from a single mother cladode was significantly lower in the blue treatment group than it was in the other treatments (Fig. 6B).

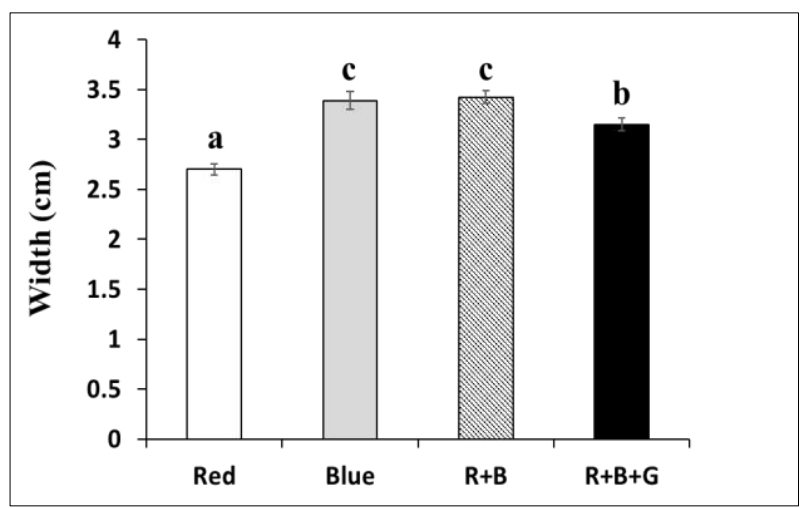

Fig. 5. Width of the daughter cladodes in each treatment group. Means followed by a different letter within each week are significantly different (Tukey's test, $\mathrm{p}<0.05$ ). Values are means $\pm \mathrm{SE}(\mathrm{n}=26)$. Red, red light treatment; Blue, blue light treatment; $\mathrm{R}+\mathrm{B}$, combined irradiance with red and blue light; $\mathrm{R}+\mathrm{B}+\mathrm{G}$, combined irradiance with red, blue, and green light

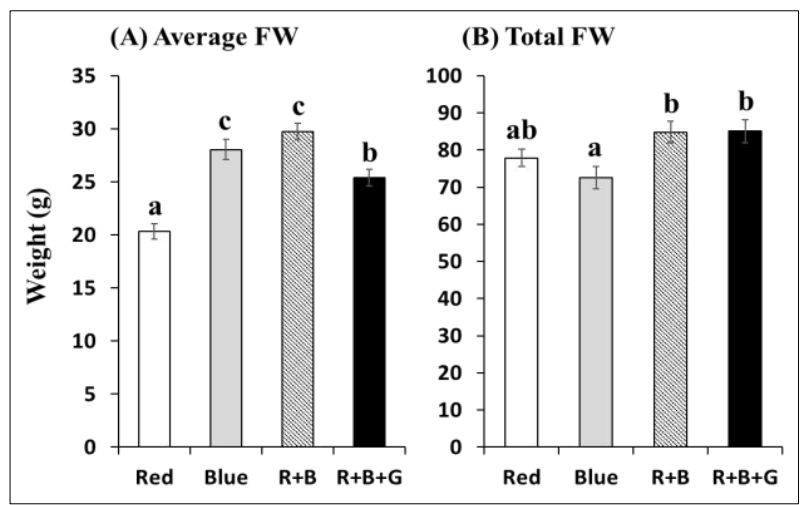

Fig. 6. Average fresh weight (FW) of the daughter cladodes (A) and total FW of the daughter cladodes harvested from a single mother cladode $(B)$ in each treatment group. Means followed by different letters are significantly different according to the least significant difference $(p<0.05)$. Values are means $\pm \operatorname{SE}(n=50$ for $[A]$ and $n=32$ for [B]). Red, red light treatment; Blue, blue light treatment; $\mathrm{R}+\mathrm{B}$, combined irradiance with red and blue light; $\mathrm{R}+\mathrm{B}+\mathrm{G}$, combined irradiance with red, blue, and green light

\section{Spine occurrence}

The percentage occurrence of spines on the daughter cladodes was lowest in the red treatment group, with no significant difference in occurrence of spines on the daughter cladodes among the other treatments (Fig. 7).

\section{DPPH radical scavenging activity}

The DPPH radical scavenging activity was highest in the blue and $\mathrm{R}+\mathrm{B}$ treatment groups, lowest in the red treatment group, and intermediate in the $\mathrm{R}+\mathrm{B}+\mathrm{G}$ treatment group (Fig. 8).

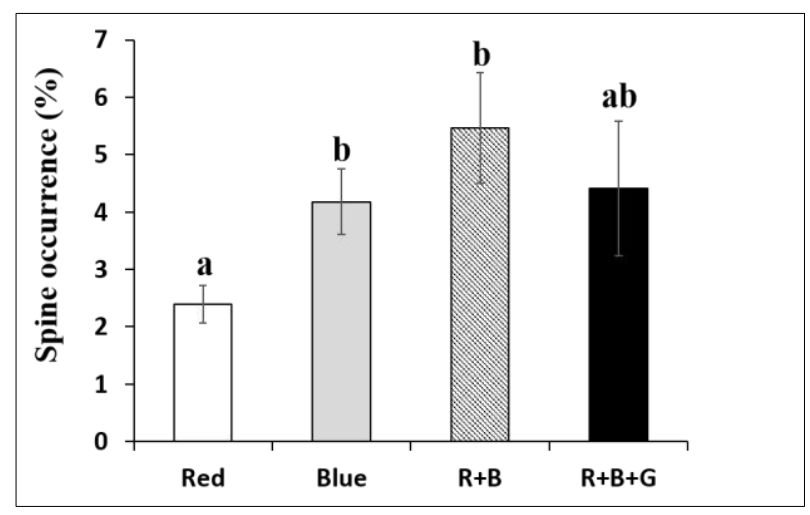

Fig. 7. Occurrence of spines on the daughter cladodes in each treatment group. Means followed by different letters are significantly different according to the least significant difference $(p<0.05)$. Values are means $\pm S E(n=26)$. Red, red light treatment; Blue, blue light treatment; $\mathrm{R}+\mathrm{B}$, combined irradiance with red and blue light; $\mathrm{R}+\mathrm{B}+\mathrm{G}$, combined irradiance with red, blue, and green light

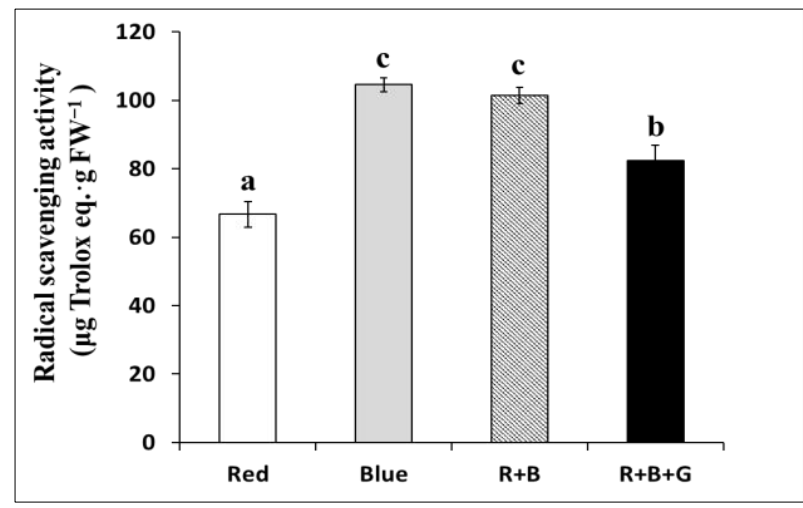

Fig. 8. 2,2-diphenyl-1-picrylhydrazyl (DPPH) radical scavenging activity of the daughter cladodes. Means followed by different letters are significantly different according to the least significant difference $(p<0.05)$. Values are means $\pm \mathrm{SE}(\mathrm{n}=10)$. Red, red light treatment; Blue, blue light treatment; $\mathrm{R}+\mathrm{B}$, combined irradiance with red and blue light; $\mathrm{R}+\mathrm{B}+\mathrm{G}$, combined irradiance with red, blue, and green light 


\section{DISCUSSION}

Edible cacti (Nopalea and Opuntia species) are characterized by their remarkable adaptation to arid and semi-arid climates. These plants exhibit crassulacean acid metabolism (CAM), a $\mathrm{CO}_{2}$ concentrating mechanism that potentially leads to higher optimal temperatures for photosynthesis (Monson 1989), and they also have certain anatomical modifications that enable them to survive droughts, such as thick cuticles and a low frequency of stomata, together with night-time $\mathrm{CO}_{2}$ uptake (Drennan \& Nobel 2000; Pimienta-Barrios et al. 2005). However, the multiple daughter cladodes that develop from the areoles of the mother cladode (Pimienta-Barrios et al. 2005) exhibit $C 3$ photosynthesis with day time stomatal opening during the early stages of development (Acevedo et al. 1983; Osmond 1978) and import water from the mother cladode (PimientaBarrios et al. 2005). The effects of temperature and $\mathrm{CO}_{2}$ concentration on the growth of Opuntia plants have been well studied (Gulmon \& Bloom 1979; North et al. 1995), with the results showing that elevated $\mathrm{CO}_{2}$ concentrations increase the daily net $\mathrm{CO}_{2}$ uptake of the cladodes and lead to increased biomass production (Cui et al. 1993; Nobel \& Israel 1994). However, few studies have investigated the relationship between the light environment and growth of edible cacti.

In this study, the daughter cladodes were developed from $N$. cochenillifera mother cladodes and continued to grow under all treatments (Fig. 4), indicating that this edible cactus can be successfully grown hydroponically using the deep-flow technique, although it is not clear whether mother cladodes also undergo $\mathrm{C} 3$ photosynthesis in these conditions. Interestingly, this cladode growth occurred despite a drastic reduction in the $\mathrm{pH}$ of the nutrient solution to around 2.5 during the course of the experiment (Fig. 3A), which may have been caused by an outflow of organic acids from the cut ends of the cladodes and/or the roots. In all treatments, the daughter cladodes that were produced were longer and narrower than is usually observed in a greenhouse (Figs. 1B and 5). The elongation growth of plant stems is affected by a number of environmental conditions, including photoperiod, temperature, and light wavelength (Hidaka et al. 2014; Shibutani \& Kinoshita 1968). Therefore, it is possible that the light conditions, including the wavelength and strength, affected the elongation growth of the daughter cladodes in this study, resulting in their slender appearance.

The elongation growth rate of the first daughter cladodes and the number of daughter cladodes produced were lowest in the blue treatment group (Fig. 4), indicating that blue light suppresses daughter cladode development compared with red light. The suppression of growth by blue light has previously been reported in many plants (Kigel \& Cosgrove 1991; Maas et al. 1995). For example, Zhao et al. (2007) showed that the amount of gibberellin $\mathrm{A}_{4}$ in the hypocotyls of Arabidopsis thaliana decreases after irradiation with blue light via cryptochrome-mediated signal transduction, resulting in the suppression of elongation growth. Thus, the suppression of growth in the daughter cladodes of $N$. cochenillifera grown under blue light may have been caused by changes in the concentrations of plant hormones, such as gibberellin.

The daughter cladodes were narrower in the red treatment group (Fig. 5), resulting in a lower average FW (Fig. 6A). However, the total FW of the daughter cladodes harvested from a single mother cladode was not low in the red treatment group due to the large number of cladodes produced (Figs. 4B and $6 \mathrm{~B}$ ). Conversely, even though the average $\mathrm{FW}$ of the daughter cladodes was relatively high in the blue treatment group, the total FW of the daughter cladodes was lowest in this group due to the low number of cladodes produced (Figs. 4B and 6). Therefore, the use of red light appears to be effective in increasing the cladode number and productivity. It has previously been shown that the red/farred light receptor phytochrome and the blue light receptor phototropin interact with each other in plants (Devlin \& Kay 2000; Hughes et al. 2012), which may also affect cladode development. The cladode width and number were lower in the $\mathrm{R}+\mathrm{B}+\mathrm{G}$ treatment group than in the $\mathrm{R}+\mathrm{B}$ treatment group (Figs. $4 \mathrm{~B}$ and 5). It has previously been reported that green light induces shade avoidance symptoms (Wang \& Folta 2013; Zhang et al. 2011) and that the addition of green light to a background of red and blue light 
causes an increase in petiole length at the expense of total leaf length in A. thaliana (Zhang et al. 2011). Therefore, it is possible that green light may have a similar effect on cladode growth. However, it is also possible that the observed difference was caused by the decreased light strength and interaction among the other light elements. Therefore, further research is required to fully understand the effect of green light on cladode growth and development.

The number of spines on the daughter cladodes was lowest in the red treatment group, with no significant difference among the other treatments (Fig. 7). Therefore, it appears that blue light is more important for spine development than red light. The spines that occur on the stem surface of most cacti, including edible cacti, have a number of beneficial functions, including participation in zoochorous dispersal (Bobich \& Nobel 2001; Frego \& Staniforth 1985), mechanical protection from herbivores (Norman \& Martin 1986), shading of the stem (Nobel et al. 1986), collection of fog to absorb water (Ju et al. 2012), and reflection of light (Loik 2008), several of which serve to reduce water loss (Stintzing $\&$ Carle 2005). However, the sharp spines that occur on the cladodes of edible cacti are one of the most undesirable characteristics for consumers and reduce their commercial value. These spines are usually burned or removed using a knife before the cactus is put on sale but cultivation techniques that can reduce the number of spines would contribute to improving the commercial value of the product. Based on the findings of this study, we believe that controlling the light environment will be useful for this purpose. However, further research is required to better understand the effects of hydroponic culture and the cultivation conditions, including temperature, humidity, and light intensity, on spine development.

The DPPH radical scavenging activity of daughter cladode extract was highest for the blue treatment group and lowest for the red treatment group (Fig. 8). Several studies have shown that the blue light enhances the antioxidant status of green vegetables by increasing the polyphenol (Johkan et al. 2010), vitamin C (Li et al. 2012), and anthocyanin (Stutte et al. 2009) contents. Similarly, our results suggest that blue light is effective in increasing the antioxidant status of $N$. cochenillifera.
Fully enclosed plant factories that use artificial light are already in use in Japan for the production of leafy vegetables. The main advantage of modern plant factories is that their controlled, optimal cultivation environment allows high-quality, pesticidefree vegetables to be produced throughout the year, increasing the safety and supply of food crops (Yamori et al. 2014). However, plant factories also have some disadvantages, such as the very high initial investment and running costs (particularly with respect to personnel, fuel, and light expenses) (Yanata \& Takata 2014). Consequently, most enclosed-type plant factories are used to grow leafy vegetables, herbs, root crops, medicinal plants, and other crops that are short in height and can be sold at high prices, whereas tomato (Solanum lycopersicum), cucumber (Cucumis sativus), eggplant (S. melongena), and seedlings of ornamental and bedding plants are produced in sunlight-based plant factories due to their relatively low running cost compared with enclosedtype factories (Kozai 2013). Edible cacti have many features that make them suitable for production in plant factories, such as their rapid growth and ability to be vegetatively propagated through the stems (in the short term until harvest). In addition, the cladodes can be planted at a high density on cultivation panels resulting in effective use of the available space, and can be grown under relatively low light intensity using artificial light. Therefore, we believe that plant factories represent powerful tools for cultivating and improving the quality of edible cacti.

The present study demonstrated that $N$. cochenillifera can be grown in an enclosed-type plant factory using DFT and that the wavelength of light strongly affects daughter cladode growth, spine development, and antioxidant activity. Cladode yield and antioxidant properties are enhanced when plants are grown under light with red and blue bands in light spectrum comparing to only blue or only red. Therefore, manipulation of the light environment could be used to improve the productivity and quality of this edible cactus. However, it is still not clear what should be the correct ratio between red and blue bands for increasing yield and improving quality of cladodes. Further research is required, however, to better understand the relationship between the light environment and development of edible cacti. 


\section{REFERENCES}

Acevedo E., Badilla I., Nobel P.S. 1983. Water relations, diurnal activity changes, and productivity of a cultivated cactus, Opuntia ficus-indica. Plant Physiology 72: 775-780. DOI: 10.1104/pp.72.3.775.

Bobich E.G., Nobel P.S. 2001. Vegetative reproduction as related to biomechanics, morphology and anatomy of four cholla cactus species in the Sonoran Desert. Annals of Botany 87: 485-493. DOI: 10.1006/anbo.2000.1360.

Cui M., Miller P.M., Nobel P.S. 1993. $\mathrm{CO}_{2}$ exchange and growth of the crassulacean acid metabolism plant Opuntia ficus-indica under elevated $\mathrm{CO}_{2}$ in opentop chambers. Plant Physiology 103: 519-524. DOI: 10.1104/pp.103.2.519.

Cruz-Hernández A., Paredes-López O. 2010. Enhancement of economical value of nopal and its fruits through biotechnology. Journal of the Professional Association for Cactus Development 12: 110-126.

Devlin P.F., Kay S.A. 2000. Cryptochromes are required for phytochrome signaling to the circadian clock but not for rhythmicity. Plant Cell 12: 2499-2510. DOI: 10.1105/tpc.12.12.2499.

du Toit R., Volsteedt Y., Apostolides Z. 2001. Comparison of the antioxidant content of fruits, vegetables and teas measured as vitamin $\mathrm{C}$ equivalents. Toxicology 166: 63-69. DOI: 10.1016/s0300-483x(01)00446-2.

Drennan P.M., Nobel P.S. 2000. Responses of CAM species to increasing atmospheric $\mathrm{CO}_{2}$ concentrations. Plant, Cell and Environment 23: 767-781. DOI: 10.1046/j.1365-3040.2000.00588.x.

El-Mostafa K., El Kharrassi Y., Badreddine A., Andreoletti P., Vamecq J., El Kebbaj M.S. et al. M. 2014. Nopal cactus (Opuntia ficus-indica) as a source of bioactive compounds for nutrition, health and disease. Molecules 19: 14879-14901. DOI: 10.3390/molecules190914879.

Frego K.A., Staniforth R.J. 1985. Factors determining the distribution of Opuntia fragilis in the boreal forest of southeastern Manitoba. Canadian Journal of Botany 63: 2377-2382. DOI: 10.1139/b85-340.

García-Saucedo P.A., Valdez-Morales M., Valverde M.E., Cruz-Hernández A., Paredes-López O. 2005. Plant regeneration of three Opuntia genotypes used as human food. Plant Cell, Tissue and Organ Culture 80: 215-219. DOI: 10.1007/s11240-004-9158-0.

Gulmon S.L., Bloom A.J. 1979. C 3 photosynthesis and high temperature acclimation of CAM in Opuntia basilaris Engelm. and Bigel. Oecologia 38: 217222. DOI: $10.1007 / \mathrm{bf00346565.}$
Guzmán-Maldonado S.H., Paredes-López O. 1999. Biotechnology for the improvement of nutritional quality of food crop plants. In: Paredes-López O. (Ed.), Molecular biotechnology for plant food production. CRC Press, p. 553-620.

Hidaka K., Okamoto A., Araki T., Miyoshi Y., Dan K., Imamura H., Kitano M. et al. 2014. Effect of photoperiod of supplemental lighting with light-emitting diodes on growth and yield of strawberry. Environmental Control in Biology 52: 63-71. DOI: 10.2525/ecb.52.63.

Hirama J. 2015. The history and advanced technology of plant factories. Environment Control in Biology 53: 47-48. DOI: 10.2525/ecb.53.47.

Horibe T., Yamada K. 2016. Hydroponics culture of edible Opuntia 'Maya': drought stress affects the development of spines on daughter cladodes. Environment Control in Biology 54: 153-156. DOI: 10.2525/ecb.54.153.

Horibe T. 2017. A cost-effective, simple, and productive method of hydroponic culture of edible Opuntia "Maya". Environment Control in Biology 55: 171174. DOI: 10.2525/ecb.55.171.

Hughes R.M., Vrana J.D., Song J., Tucker C.L. 2012. Light-dependent, dark-promoted interaction between Arabidopsis cryptochrome 1 and phytochrome B proteins. Journal of Biological Chemistry 287: 22165-22172. DOI: 10.1074/jbc.m112.360545.

Ju J., Bai H., Zheng Y., Zhao T., Fang R., Jiang L. 2012. A multi-structural and multi-functional integrated fog collection system in cactus. Nature Communications 3: 1247. DOI: 10.1038/ncomms2253.

Johkan M., Shoji K., Goto F., Hashida S., Yoshihara T. 2010. Blue light-emitting diode light irradiation of seedlings improves seedling quality and growth after transplanting in red leaf lettuce. HortScience 45: 1809-1814. DOI: 10.21273/hortsci.45.12.1809.

Kigel J., Cosgrove D.J. 1991. Photoinhibition of stem elongation by blue and red light. Effects on hydraulic and cell wall properties. Plant Physiology 95: 1049-1056. DOI: 10.1104/pp.95.4.1049.

Kozai T. 2013. Plant factory in Japan - current situation and perspectives. Chronica Horticulturae 53: 8-11.

Lakkireddy K.K.R., Kasturi K., Sambasiva Rao R.K.S. 2012. Role of hydroponics and aeroponics in soilless culture in commercial food production. Journal of Agricultural Science and Technology 1: 26-35.

Li H., Tang C., Xu Z., Liu X., Han X. 2012. Effects of different light sources on the growth of non-heading Chinese cabbage (Brassica campestris L.). 
Journal of Agricultural Science 4: 262-273. DOI: 10.5539/jas.v4n4p262.

Littlejohn R.O., Ku M.S.B. 1985. Light and temperature regulation of early morning crassulacean acid metabolism in Opuntia erinacea var columbiana (Griffiths) L. Benson. Plant Physiology 77: 489491. DOI: $10.1104 / p p .77 .2 .489$.

Loik M.E. 2008. The effect of cactus spines on light interception and Photosystem II for three sympatric species of Opuntia from the Mojave Desert. Physiologia Plantarum 134: 87-98. DOI: 10.1111/j.1399-3054.2008.01110.x.

Maas F.M., Bakx E.J., Morris D.A. 1995. Photocontrol of stem elongation and dry weight portioning in Phaseolus vulgaris L. by the blue-light content of photosynthetic photon flux. Journal of Plant Physiology 146: 665-671. DOI: 10.1016/s01761617(11)81930-9.

Monson R.K. 1989. On the evolutionary pathways resulting in $\mathrm{C}_{4}$ photosynthesis and crassulacean acid metabolism (CAM). Advances in Ecological Research 19: 57-110. DOI: 10.1016/s0065-2504(08)60157-9.

Mortensen L.M., Strømme E. 1987. Effects of light quality on some greenhouse crops. Scientia Horticulturae 33: 27-36. DOI: 10.1016/03044238(87)90029-X.

Nobel P.S., Geller G.N., Kee S.C., Zimmerman A.D. 1986. Temperatures and thermal tolerances for cacti exposed to high temperatures near the soil surface. Plant, Cell and Environment 9: 279-287. DOI: 10.1111/1365-3040.ep11611688.

Nobel P.S., Israel A.A. 1994. Cladode development, environmental responses of $\mathrm{CO}_{2}$ uptake, and productivity for Opuntia ficus-indica under elevated $\mathrm{CO}_{2}$. Journal of Experimental Botany 45: 295-303. DOI: 10.1093/jxb/45.3.295.

Norman F., Martin C.E. 1986. Effects of spine removal on Coryphantha vivipara in central Kansas. American Midland Naturalist 116: 118-124. DOI: 10.2307/2425943.

North G.B., Lin Moore T., Nobel P.S. 1995. Cladode development for Opuntia ficus-indica (Cactaceae) under current and doubled $\mathrm{CO}_{2}$ concentrations. American Journal of Botany 82: 159-166. DOI: $10.2307 / 2445524$.

Ogawa A., Eguchi T., Toyofuku K. 2012. Cultivation methods for leafy vegetables and tomatoes with low potassium content for dialysis patients. Environment Control in Biology 50: 407-414. DOI: 10.2525/ecb.50.407.
Osmond C.B. 1978. Crassulacean acid metabolism: a curiosity in context. Annual Review of Plant Physiology 29: 379-414. DOI: 10.1146/annurev.pp.29.060178.002115.

Pimienta-Barrios E., Zañudo-Hernandez J., Rosas-Espinoza V.C., Valenzuela-Tapia A., Nobel P.S. 2005. Young daughter cladodes affect $\mathrm{CO}_{2}$ uptake by mother cladodes of Opuntia ficus-indica. Annals of Botany 95: 363-369. DOI: 10.1093/aob/mci034.

Shetty A.A., Rana M.K., Preetham S.P. 2012. Cactus: a medicinal food. Journal of Food Science and Technology 49: 530-536. DOI: 10.1007/s13197-0110462-5.

Shibutani S., Kinoshita K. 1968. Studies on the ecological adaptation of lettuce. III. The ecological adaptation of Great Lakes 54 in the growth cabinet in which the temperature is controlled. Scientific reports of the Faculty of Agriculture, Okayama University 32: 2534. [in Japanese with English abstract]

Silos-Espino H., Valdez-Ortiz A., Rascón-Cruz Q., Rodríguez-Salazar E., Paredes-López O. 2006. Genetic transformation of prickly-pear cactus (Opuntia ficus-indica) by Agrobacterium tumefaciens. Plant Cell, Tissue and Organ Culture 86: 397-403. DOI: $10.1007 / \mathrm{s} 11240-006-9123-1$.

Stefanelli D., Winkler S., Jones R. 2011. Reduced nitrogen availability during growth improves quality in red oak lettuce leaves by minimizing nitrate content, and increasing antioxidant capacity and leaf mineral content. Agricultural Sciences 2: 477-486. DOI: 10.4236/as.2011.24061.

Stintzing F.C., Carle R. 2005. Cactus stems (Opuntia spp.): a review on their chemistry, technology, and uses. Molecular Nutrition and Food Research 49: 175-194. DOI: 10.1002/mnfr.200400071.

Stutte G.W., Edney S., Skerritt T. 2009. Photoregulation of bioprotectant content of red leaf lettuce with light-emitting diodes. HortScience 44: 79-82. DOI: 10.21273/hortsci.44.1.79.

Tinyane P.P., Sivakumar D., Soundy P. 2013. Influence of photo-selective netting on fruit quality parameters and bioactive compounds in selected tomato cultivars. Scientia Horticulturae 161: 340-349. DOI: 10.1016/j.scienta.2013.06.024.

Wahome P.K., Oseni T.O., Masarirambi M.T., Shongwe V.D. 2011. Effects of different hydroponics systems and growing media on the vegetative growth, yield and cut flower quality of gypsophila (Gypsophila paniculata L.). World Journal of Agricultural Sciences 7: 692-698. 
Wang H.-J., Wu L.-H., Wang M.-Y., Zhu Y.-H., Tao Q.N., Zhang F.-S. 2007. Effects of amino acids replacing nitrate on growth, nitrate accumulation, and macroelement concentrations in pak-choi (Brassica chinensis L.). Pedosphere 17: 595-600. DOI: 10.1016/s1002-0160(07)60070-8.

Wang Y., Folta K.M. 2013. Contributions of green light to plant growth and development. American Journal of Botany 100: 70-78. DOI: 10.3732/ajb.1200354.

Yamori W., Zhang G., Takagaki M., Maruo T. 2014. Feasibility study of rice growth in plant factories. Rice Research 2(1); 119; 6 p. DOI: 10.4172/jrr.1000119.

Yanagi T., Yachi T., Okuda N., Okamoto K. 2006. Light quality of continuous illuminating at night to induce floral initiation of Fragaria chiloensis L. CHI-
24-1. Scientia Horticulturae 109: 309-314. DOI: 10.1016/j.scienta.2006.05.009.

Yanata S., Takata K. 2014. Plant factory: The possible measures to revitalize the Wakayama's economy. Regional Studies 43 (revised edition). Institute of Economic Research, Faculty of Economics, Wakayama University, $22 \mathrm{p}$.

Zhao X., Yu X., Foo E., Symons G.M., Lopez J., Bendehakkalu K.T. et al. 2007. A study of gibberellin homeostasis and cryptochrome-mediated blue light inhibition of hypocotyl elongation. Plant Physiology 145: 106-118. DOI: 10.1104/pp.107.099838.

Zhang T., Maruhnich S., Folta K.M. 2011. Green light induces shade avoidance symptoms. Plant Physiology 157: 1528-1536. DOI: 10.1104/pp.111.180661. 